
\title{
25 Research Soure \\ Prevalence and impact of metabolic syndrome in patients with alcohol use disorder
}

\section{Anna Hernández-Rubio}

Hospital Universitari Germans Trias i Pujol

Arantza Sanvisens

Institut de Recerca Contra la Leucemia Josep Carreras

\section{Ferran Bolao}

Bellvitge University Hospital: Hospital Universitari de Bellvitge

\section{Isabel Cachón-Suárez}

Bellvitge University Hospital: Hospital Universitari de Bellvitge

\section{Carme Garcia-Martín}

Hospital Germans Trias i Pujol: Hospital Universitari Germans Trias i Pujol

\section{Antoni Short}

Son Espases University Hospital: Hospital Universitari Son Espases

\section{Ramón Bataller}

Pittsburgh Liver Research Center

Roberto Muga ( $\nabla$ rmuga.germanstrias@gencat.cat)

University Hospital Germans Trias i Pujol: Hospital Universitari Germans Trias i Pujol https://orcid.org/0000-0001-6301-431X

\section{Original investigation}

Keywords: metabolic syndrome, alcohol use disorder, hyperuricemia, cardiovascular disease

Posted Date: June 30th, 2021

DOl: https://doi.org/10.21203/rs.3.rs-655958/v1

License: (c) (1) This work is licensed under a Creative Commons Attribution 4.0 International License. Read Full License 


\section{Abstract \\ Background}

the metabolic syndrome (MetS) is an inflammatory disorder predisposes to type 2 diabetes and cardiovascular disease (CVD). We aimed to analyze the prevalence and associations of MetS in patients with alcohol use disorder.

\section{Methods}

cross-sectional study in heavy drinkers admitted for treatment of alcohol use disorder between 2013 and 2017. Medical comorbidity, anthropometric data, alcohol use and biological parameters were obtained at admission. MetS was established according to the harmonized definition of 2009. Logistic regression models were used to analyze associations of MetS.

\section{Results}

728 patients (22\% women) were included; median age was 47 years (IQR:40-53.5) and median alcohol consumption was $160 \mathrm{~g} /$ day (IQR:115-240). Overall, $9.2 \%, 26.7 \%$, and $6.8 \%$ of the patients had type 2 diabetes, hypertension, and CVD, respectively. BMI was $25.0 \mathrm{~kg} / \mathrm{m}^{2}$ (IQR:22.1-28.7) and prevalence of MetS was $13.9 \%$. The multivariate analysis showed a significant dose-response effect of estimated glomerular filtration (eGFR) and MetS: relative to patients with eGFR $>90 \mathrm{~mL} / \mathrm{min}$, those with eGFR (60$90 \mathrm{~mL} / \mathrm{min}$ ) and those with eGFR $<60 \mathrm{~mL} / \mathrm{min}$ were 1.93 times (95\% Cl: $1.18-3.15)$ and 5.61 times (95\% Cl: 1.66-19.0) more likely to have MetS, respectively. In addition, MetS was significantly associated with hyperuricemia (OR $=2.28,95 \% \mathrm{Cl}: 1.36-3.82)$ and elevated serum GGT (OR $=3.67,95 \% \mathrm{Cl}: 1.80-7.46)$. Furthermore, for every increase of 1 year in age, the probability of MetS increased significantly $(O R=1.03$, $95 \%$ Cl: $1.01-1.05)$.

\section{Conclusions}

MetS in heavy drinkers is independently associated with reduced kidney function and metabolic risk factors including hyperuricemia and elevated serum GGT.

\section{Background}

The metabolic syndrome (MetS) is a cluster of clinical and biological findings including obesity, hypertension, glucose intolerance, and dyslipidemia, which are related to each other and confer a higher risk of cardiovascular disease (CVD) and type 2 diabetes (1). The prevalence of MetS is increasing in western countries and it is estimated to affect almost a quarter of the general European population $(2,3)$. 
In 1998, the World Health Organization defined MetS as the presence of glucose intolerance, low level of HDL cholesterol, high triglycerides, obesity, and/or hypertension (4). Subsequent modifications were introduced and several definitions appeared within a decade (5-7). In 2009, the American Heart Association and National Heart, Lung and Blood Institute, International Diabetes Federation, World Heart Federation, International Atherosclerosis Society, and International Association for the Study of Obesity established a harmonized definition that have been maintained to date (8). However, some authors proposed the use of apolipoprotein B to better identify individuals with atherogenic dyslipidemia (9). Moreover, some studies focus on characterizing premorbid MetS, since a proportion of individuals do not develop type 2 diabetes or CVD in the initial stages of the syndrome $(10,11)$. In clinical practice, the identification of individuals with premorbid MetS can be useful by revealing a patient phenotype that would benefit from pharmacologic and non-pharmacologic interventions to avoid the incidence of cardiometabolic complications.

MetS is an inflammatory disorder and insulin resistance is the main underlying pathophysiological mechanism. Insulin resistance is promoted by overweight/obesity, which in turn induces a proinflammatory state. MetS has also been associated with neurohormonal and hepatic alterations through mechanisms such as oxidative stress and chronic inflammation (12).

Excessive alcohol consumption has been associated with each of the components of MetS; specifically, alcohol abuse is associated with a higher risk of CVD due to arterial hypertension and dyslipidemia, among other mechanisms $(13,14)$. Moreover, unhealthy lifestyles (i.e., sedentarism, tobacco smoking) may be relatively frequent in individuals with alcohol misuse. In fact, CVD is the leading cause of death in patients with alcohol use disorder (AUD)(15). In addition, the incidence of type 2 diabetes in heavy drinkers may be higher than observed in the general population (16). On the other hand, the relationship between excessive alcohol consumption and overweight is controversial, and the association between the amount and type of alcohol with obesity has not been fully established. Nevertheless, cardiometabolic factors and MetS have been poorly studied in heavy drinkers as compared to other populations. We hypothesize that chronic, excessive alcohol consumption favors the appearance of pro-inflammatory alterations that predisposes to both type 2 diabetes and atherosclerotic CVD. Moreover, co-occurrence of liver damage (i.e., alcoholic steatohepatitis) in the context of excessive alcohol consumption can contribute to the inflammatory response thus increasing the cardiometabolic risk. The objective of this study was to analyze the impact and associations of MetS in heavy drinkers seeking treatment of alcohol abuse or dependence.

\section{Methods}

This was a cross-sectional study in patients admitted to two hospital addiction units in metropolitan Barcelona, Spain: Hospital Universitari de Bellvitge in L'Hospitalet de Llobregat and Hospital Universitari Germans Trias i Pujol in Badalona. All patients had been consecutively admitted between January 2013 and November 2017 and were referred by primary care physicians and specialists in Addiction medicine 
at outpatient clinics. All patients were diagnosed with AUD according to the Diagnostic and Statistical Manual of Mental Disorders, 5th edition.

On the day of admission, patients underwent an interview to collect data regarding sociodemographic variables, medical comorbidity (i.e., type 2 diabetes, hypertension), antecedent of CVD (i.e., coronary artery disease, ischemic stroke, peripheral vascular disease), and characteristics of alcohol consumption (i.e., daily amount consumed, age of starting alcohol consumption, duration of AUD, previous treatment of the disorder); alcohol consumption was quantified as grams of ethanol per day. Anthropometric data (height and weight) were also recorded.

Peripheral blood samples for determining biochemical and hematological parameters were collected on the second day of admission after overnight fasting. Blood samples were collected in heparin plasma tubes and transferred to the laboratories. Hematological parameters, such as hemoglobin, erythrocyte sedimentation rate (ESR), mean corpuscular volume, and serum folate, were measured using automated hematological analyzers. Biochemical parameters, such as glucose, urate, albumin, total cholesterol, HDL cholesterol, triglycerides, total bilirubin, creatinine, uric acid, aspartate aminotransferase, alanine aminotransferase (ALT), and gamma-glutamyl transferase (GGT), were measured with standard enzymatic methods using multichannel automatic analyzers. The analytical alterations were defined based on the reference values determined by the laboratories. The established cut-off value for serum uric acid (SUA) was $>7.2 \mathrm{mg} / \mathrm{dL}$ in men and $>6 \mathrm{mg} \mathrm{dL}$ in women. High levels were defined as $>0.90$ $\mathrm{mg} / \mathrm{dL}$ for creatinine, $>50 \mathrm{U} / \mathrm{L}$ for GGT, and $>40 \mathrm{U} / \mathrm{L}$ for ALT. Altered ESR was defined as $>20 \mathrm{~mm}$. The clinical chemistry and hematology laboratories complied with the UNE-EN-IS09001:2015 standards and were accredited in their respective areas.

Renal function was assessed by the estimated Glomerular Filtration Rate (eGFR), calculated using creatinine, age, sex, and ethnicity through the Chronic Kidney Disease Epidemiology Collaboration Eq. (17). Highly reduced and mildly reduced eGFR values were defined as $\leq 60 \mathrm{~mL} / \mathrm{min} / 1.73 \mathrm{~m}^{2}$ and $60-$ $90 \mathrm{~mL} / \mathrm{min} / 1.73 \mathrm{~m}^{2}$, respectively.

Pharmacologic treatment during admission included benzodiazepines, vitamin B complex, and other pharmacotherapy depending on the severity of alcohol withdrawal.

The length of hospital stay was 7 days on average, and patients were advised to follow visit and control protocols at the outpatient clinic after discharge.

\section{Metabolic syndrome}

MetS was defined according to the diagnostic criteria of 2009 (8) that required the presence of three or more of the following: 1) central obesity; 2 ) triglycerides $\geq 150 \mathrm{mg} / \mathrm{dL}$ or treatment with fibrates, nicotinic acid, or $\omega-3$ fatty acids; 3) HDL cholesterol $<40 \mathrm{mg} / \mathrm{dL}$ in men and $<50 \mathrm{mg} / \mathrm{dL}$ in women or treatment with fibrates or nicotinic acid; 4) systolic blood pressure $\geq 130 \mathrm{mmHg}$ and/or diastolic blood pressure $\geq$ $85 \mathrm{mmHg}$ or antihypertensive treatment; and 5) elevated fasting glucose $\geq 100 \mathrm{mg} / \mathrm{dL}$ or treatment for 
type 2 diabetes. For the purpose of this study, central obesity was assumed if the BMI at admission was $>30 \mathrm{~kg} / \mathrm{m}^{2}(18,19)$. Moreover, atherogenic dyslipidemia was defined as the simultaneous alteration of elevated triglycerides $(>150 \mathrm{mg} / \mathrm{dL}$ ) and low HDL cholesterol $(<40 \mathrm{mg} / \mathrm{dL}$ in men and $<50 \mathrm{mg} / \mathrm{dL}$ in women).

\section{Selection criteria}

There were 949 consecutive admissions of 739 patients during the study period, with $99 \%$ of caucasian origin. For those patients who were admitted more than once, the first admission was selected. Eleven patients were excluded due to insufficient information to determine MetS.

\section{Ethical considerations}

All patients provided written informed consent, and the study design was approved by the Ethics Committee of the Hospital Universitari Germans Trias i Pujol (approval number CEXT042013). The methods complied with the ethical standards for medical research and the principles of good clinical practice in accordance with the World Medical Association's Declaration of Helsinki.

\section{Statistical analysis}

Descriptive statistics were expressed as median (interquartile range [IQR]) for quantitative variables and as absolute frequencies and percentages for qualitative variables. To analyze differences in those with and without MetS we used the chi-square test for qualitative variables and the t-test for analyzing mean differences in the quantitative variables.

Logistic regression models were used to analyze associations of behavioral and biological variables with MetS. The covariates included in the multivariate analysis were those that were found to be statistically significant in the univariate analysis. The Hosmer-Lemeshow test was used for analyzing goodness of fit.

A sensitivity analysis was performed with a cut-off point of $>25 \mathrm{~kg} / \mathrm{m}^{2}$ for body mass index (BMI) as a MetS criteria.

P-values $<0.05$ were considered statistically significant. Statistical analyses were performed using Stata software (version 11.1, College Station, Texas, USA).

\section{Results}

This study included 728 patients ( $78 \%$ men) with a median age of 47 years (IQR: $40-53.5$ years) who started drinking alcohol at 16 years (IQR: 16-18 years). Among them, the median alcohol consumption was $160 \mathrm{~g} /$ day (IQR: $115-240 \mathrm{~g} /$ day). Moreover, $92.5 \%$ of the patients were or had been smokers and $14.4 \%$.

Table 1 shows the sociodemographic, alcohol use characteristics and blood parameters of patients at admission. 
Table 1

Characteristics of 728 patients admitted for detoxification with and without Metabolic Syndrome

\begin{tabular}{|c|c|c|c|c|}
\hline & $\begin{array}{l}N=728 \\
n(\%)\end{array}$ & $\begin{array}{l}\text { No MetS } \\
\mathrm{N}=627 \\
\mathrm{n}(\%)\end{array}$ & $\begin{array}{l}\text { MetS } \\
N=101 \\
n(\%)\end{array}$ & $\begin{array}{l}p \\
\text { value }\end{array}$ \\
\hline \multicolumn{5}{|l|}{ Sociodemographic } \\
\hline Women & $160(22.0)$ & $137(21.8)$ & $23(22.8)$ & 0.835 \\
\hline Age at admission, median (IQR) & $47[40-53.5]$ & $46[40-53]$ & $51[45-55]$ & $\hat{0.001}$ \\
\hline \multicolumn{5}{|l|}{ Alcohol consumption } \\
\hline $\begin{array}{l}\text { Age at starting alcohol use, median (IQR) }(\mathrm{n}= \\
673)\end{array}$ & 16 [16-18] & 16 [16-18] & 16 [16-20] & 0.223 \\
\hline Antecedent of alcohol treatment $(n=673)$ & $490(72.8)$ & $422(72.9)$ & $68(72.3)$ & 0.912 \\
\hline $\begin{array}{l}\text { Amount of alcohol consumption (g/day), } \\
\text { median }(I Q R)(\mathrm{n}=678)\end{array}$ & $\begin{array}{l}160[115- \\
240]\end{array}$ & $\begin{array}{l}160[110- \\
240]\end{array}$ & $\begin{array}{l}180[120- \\
250]\end{array}$ & 0.113 \\
\hline Hematology & $\begin{array}{l}\text { median } \\
\text { (IQR) }\end{array}$ & $\begin{array}{l}\text { median } \\
\text { (IQR) }\end{array}$ & $\begin{array}{l}\text { median } \\
\text { (IQR) }\end{array}$ & \\
\hline Hemoglobin $(g / d L)(n=726)$ & $\begin{array}{l}14.3[13.2- \\
15.4]\end{array}$ & $\begin{array}{l}14.3[13.2- \\
15.4]\end{array}$ & $\begin{array}{l}14.5[13.3- \\
15.6]\end{array}$ & 0.430 \\
\hline $\operatorname{ESR}(s)(n=687)$ & $8[4-18]$ & $8[4-17]$ & $10[6-24]$ & 0.001 \\
\hline $\operatorname{MCV}(f)(n=717)$ & $\begin{array}{l}96[92.1- \\
100.4]\end{array}$ & $\begin{array}{l}96[101- \\
92.2]\end{array}$ & $\begin{array}{l}95[92- \\
100]\end{array}$ & 0.238 \\
\hline Fibrinogen $(g / L)(n=689)$ & $\begin{array}{l}3.1[2.6- \\
3.9]\end{array}$ & $\begin{array}{l}3.1[2.5- \\
3.8]\end{array}$ & $\begin{array}{l}3.4[2.7- \\
4.2]\end{array}$ & 0.013 \\
\hline Serum folate $(\mathrm{ng} / \mathrm{mL})(\mathrm{n}=606)$ & $\begin{array}{l}5.1[3.4- \\
7.7]\end{array}$ & $\begin{array}{l}5.1[3.4- \\
7.6]\end{array}$ & $\begin{array}{l}6.0[3.1- \\
9.5]\end{array}$ & 0.249 \\
\hline \multicolumn{5}{|l|}{ Biochemistry parameters } \\
\hline Urate $(\mathrm{mg} / \mathrm{dL})$ & $\begin{array}{l}5.2[4.3- \\
6.3]\end{array}$ & $\begin{array}{l}5.1[4.2- \\
6.1]\end{array}$ & $5.9[5-7.3]$ & $\begin{array}{l}<.001 \\
0.01\end{array}$ \\
\hline Protein $(\mathrm{g} / \mathrm{L})(\mathrm{n}=727)$ & $67[63-72]$ & $67[63-72]$ & $68[64-72]$ & 0.464 \\
\hline Albumin $(g / L)(n=718)$ & $\begin{array}{l}39.9 \text { [36.8- } \\
42.3]\end{array}$ & $\begin{array}{l}39.8[36.7- \\
42]\end{array}$ & $\begin{array}{l}40[37.8- \\
43.4]\end{array}$ & 0.205 \\
\hline
\end{tabular}

ESR: erythrocyte sedimentation rate; MCV: mean corpuscular volume; eGFR: estimated glomerular filtration rate; AST: aspartate aminotransferase, ALT: alanine aminotransferase; GGT: gammaglutamyl transferase 


\begin{tabular}{|c|c|c|c|c|}
\hline & $\begin{array}{l}N=728 \\
n(\%)\end{array}$ & $\begin{array}{l}\text { No MetS } \\
\mathrm{N}=627 \\
\mathrm{n}(\%)\end{array}$ & $\begin{array}{l}\text { MetS } \\
\mathrm{N}=101 \\
\mathrm{n}(\%)\end{array}$ & $\begin{array}{l}p \\
\text { value }\end{array}$ \\
\hline Creatinine $(\mathrm{mg} / \mathrm{dL})(\mathrm{n}=718)$ & $\begin{array}{l}0.79[0.68- \\
0.92]\end{array}$ & $\begin{array}{l}0.79[0.68- \\
0.9]\end{array}$ & $\begin{array}{l}0.83[0.69- \\
0.97]\end{array}$ & 0.021 \\
\hline Total bilirubin $(\mathrm{mg} / \mathrm{dL})(\mathrm{n}=718)$ & $\begin{array}{l}0.70[0.49- \\
1.11]\end{array}$ & $\begin{array}{l}0.7[0.5- \\
1.1]\end{array}$ & $0.6[0.5-1.0]$ & 0.346 \\
\hline eGFR $(m L / m i n)(n=724)$ & $\begin{array}{l}105.5[90.4- \\
123.3]\end{array}$ & $\begin{array}{l}106.4[91.7- \\
123.7]\end{array}$ & $\begin{array}{l}94.8 \text { [82.3- } \\
118.8]\end{array}$ & 0.001 \\
\hline AST (U/L) & $38[22-72.3]$ & $\begin{array}{l}27.8[21.6- \\
74]\end{array}$ & $41[24-70]$ & 0.678 \\
\hline $\operatorname{ALT}(U / L)(n=724)$ & $32[18-55.5]$ & $\begin{array}{l}31 \text { [17.4- } \\
54]\end{array}$ & $36[23-61]$ & 0.017 \\
\hline AST/ALT $(n=724)$ & $\begin{array}{l}1.2[0.9- \\
1.7]\end{array}$ & $\begin{array}{l}1.2[0.9- \\
1.7]\end{array}$ & $1[0.7-1.5]$ & $\begin{array}{l}<.001 \\
0.00\end{array}$ \\
\hline GGT $(U / L)(n=720)$ & $\begin{array}{l}120.8[49.9- \\
325.5]\end{array}$ & $\begin{array}{l}116[43.8- \\
317]\end{array}$ & $\begin{array}{l}134.4[75- \\
435]\end{array}$ & 0.027 \\
\hline $\begin{array}{l}\text { ESR: erythrocyte sedimentation r } \\
\text { filtration rate; AST: aspartate ami } \\
\text { glutamyl transferase }\end{array}$ & $\begin{array}{l}\text { corpuscular } \\
\text { LT: alanine }\end{array}$ & $\begin{array}{l}\text { ume; eGFR: } \\
\text { notransfera }\end{array}$ & $\begin{array}{l}\text { nated glome } \\
\text { ST: gamm }\end{array}$ & \\
\hline
\end{tabular}

Regarding pre-existing medical co-morbidity, $26.7 \%, 9.2 \%$, and $6.8 \%$ of the patients had a history of hypertension, type 2 diabetes, and CVD, respectively. Overall, the median BMI at admission was 25.0 $\mathrm{Kg} / \mathrm{m}^{2}$ (IQR: $22.1-28.7 \mathrm{~kg} / \mathrm{m}^{2}$ )

Prevalence of hypertriglyceridemia, hyperglycemia and low HDL cholesterol was $33.2 \%, 27.1 \%$ and $20.1 \%$, respectively.

Prevalence and Characteristics of MetS patients

The prevalence of MetS was 13.9\% (101/728) with no differences between men and women. Among the patients with MetS, $27.7 \%$ had a history of type 2 diabetes, and $78.2 \%$ showed elevated fasting glucose levels at admission. Furthermore, $86.9 \%$ of MetS patients had obesity, $70.3 \%$ had hypertension, $15.3 \%$ had a history of CVD, $80.2 \%$ had high triglycerides, and $67.3 \%$ had low HDL cholesterol ( $50 \%$ in men and $66.7 \%$ in women). The prevalence of atherogenic dyslipidemia among those with MetS was $70.2 \%$.

Associations of MetS

MetS patients were older (51 years vs. 46 years, $p<0.001$ ) as compared to those without MetS (Table 1). 
Figure 1 shows the prevalence of MetS according to sex and age groups ( $<40$ years, $40-44$ years, 45-49 years, $50-54$ years, $55-59$ years, and $\geq 60$ years). The prevalence of MetS increased in each age group up to the 50-54 years age group and decreased in those older than 55 years.

MetS patients had higher values of ESR $(p=0.001)$ and fibrinogen $(p=0.013)$, as well as a higher prevalence of hyperuricemia (31.7\% vs. $12.1 \%, p<0.001)$, GGT $>50 \mathrm{U} / \mathrm{L}(90.1 \%$ vs. $71.9 \%, \mathrm{p}<0.001)$ and serum creatinine $>0.90 \mathrm{mg} / \mathrm{dL}(37.6 \%$ vs. $24.6 \%, p=0.006)$ as compared to those without MetS. There was an association between eGFR and MetS in univariate analysis: prevalence of MetS was $11.0 \%$, $20.6 \%$, and $50.0 \%$ for eGFR $>90 \mathrm{~mL} / \mathrm{min}$, eGFR between $60-90 \mathrm{~mL} / \mathrm{min}$, and eGFR $<60 \mathrm{~mL} / \mathrm{min}$, respectively $(p<0.001)$. Figure 2 shows the odds ratio (ORs) of presenting MetS as a function of biological alterations.

The multivariate analysis showed that age, eGFR, SUA, and serum GGT were independently associated with MetS (Table 2). Specifically, there was a statistically significant, dose-response effect between the eGFR and MetS; relative to patients with eGFR $>90 \mathrm{~mL} / \mathrm{min}$, those with eGFR between $60-90 \mathrm{~mL} / \mathrm{min}$ and those with eGFR $<60 \mathrm{~mL} / \mathrm{min}$ were 1.93 (95\% confidence interval [Cl]: 1.18-3.15) and 5.61 (95\% Cl: 1.66-19.0) times more likely to have MetS, respectively. Furthermore, the odds of MetS were significantly higher in patients with hyperuricemia $(\mathrm{OR}=2.28,95 \% \mathrm{Cl}$ : $1.36-3.82)$ as compared to those with normal SUA levels, as well as in those with serum GGT $>50 \mathrm{U} / \mathrm{L}(\mathrm{OR}=3.67,95 \% \mathrm{Cl}: 1.80-7.46)$ as compared to those with normal serum GGT levels. In addition, MetS was significantly associated with age $(\mathrm{OR}=1.03$; $95 \% \mathrm{Cl}: 1.01-1.05$, for every increase of 1 year in age). 
Table 2

Logistic regression model for the associations of MetS in 728 patients with alcohol abuse or dependence admitted for detoxification.

\begin{tabular}{|c|c|c|c|c|}
\hline & OR $(95 \% \mathrm{Cl})$ & $\mathrm{p}$ value & $\begin{array}{l}\text { Multivariate } \\
\text { aOR }(95 \% \mathrm{Cl})\end{array}$ & $\mathrm{p}$ value \\
\hline Age: increase of 1 year & $1.04(1.02-1.06)$ & $<0.001$ & $1.03(1.01-1.05)$ & 0.013 \\
\hline eGFR (mL/min) & 1 & 0.002 & 1 & 0.008 \\
\hline$>90$ & $2.10(1.32-3.33)$ & $<0.001$ & $1.93(1.18-3.15)$ & 0.006 \\
\hline $60-90$ & $8.08(2.74-23.8)$ & & $5.61(1.66-19.0)$ & \\
\hline \multicolumn{5}{|l|}{$<60$} \\
\hline GGT > 50 (U/L) & $3.56(1.81-6.99)$ & $<0.001$ & $3.67(1.80-7.46)$ & $<0.001$ \\
\hline Hyperuricemia* & $3.36(2.07-5.45)$ & $<0.001$ & $2.28(1.36-3.82)$ & 0.002 \\
\hline \multicolumn{5}{|c|}{ * urate $>7.2 \mathrm{mg} / \mathrm{dL}$ in men and $>6 \mathrm{mg} \mathrm{dL}$ in women } \\
\hline \multicolumn{5}{|c|}{ eGFR: estimated glomerular filtration rate; GGT: gamma-glutamyl transferase; OR: odds ratio } \\
\hline \multicolumn{5}{|c|}{$\begin{array}{l}\text { ESR: erythrocyte sedimentation rate; eGFR: estimated glomerular filtration rate; AST: aspartate } \\
\text { aminotransferase, ALT: alanine aminotransferase; GGT: gamma-glutamyl transferase; OR: odds ratio }\end{array}$} \\
\hline
\end{tabular}

The regression model showed adequate fit as measured by the Hosmer-Lemeshow statistic $\left(\chi^{2}=182.1, p\right.$ $=0.974)$.

Sensitivity analysis

A sensitivity analysis taking into account BMI values $>25 \mathrm{~kg} / \mathrm{m}^{2}$ showed a MetS prevalence of $20.5 \%$, and the associations with MetS were consistent with those presented in the main analysis.

\section{Discussion}

Behind smoking and obesity, excessive alcohol consumption is the third leading cause of premature death in western countries. However, the effect of harmful drinking on the risk of MetS is partially known. This study in middle-aged patients starting a treatment for alcohol abuse or dependence shows that prevalence of MetS is lower than that reported in the limited literature (20). The relatively low prevalence of MetS in this large series might be related to the observed proportion of heavy drinkers without a history of cardiometabolic disease (i.e, coronary artery disease, type 2 diabetes) thus suggesting that the majority of cases were premorbid for MetS. Interestingly, prevalence of premorbid MetS in the Spanish general population is around $17 \%$ (21) and mainly related to both overweight/obesity and hypertension. Moreover, prevalence of MetS may vary depending on the case definition, selection of patients, age, sex, ethnicity, and geographic area (22). In this regard, the only systematic review and meta-analysis of 
alcohol-related MetS was published in 2016, which included five studies and an estimated mean prevalence of $19.3 \%$ (95\% Cl: 14.3-25.6) (20); four of the five studies analyzed less than 200 patients without reporting associations of MetS and the remaining focused on the risk factors.

Our results in this series of apparently asymptomatic heavy drinkers primarily admitted for the treatment of the disorder indicate that renal function plays a role in the alcohol-related MetS. Furthermore, the significant dose-response effect of declining renal function on MetS is observed in those with mild renal impairment. Relative to those with normal eGFR, patients with eGFR $<60 \mathrm{~mL} / \mathrm{min}$ were more than five times more likely to meet criteria of MetS. The MetS can increase the risk of kidney disease via mechanisms linked to chronic inflammation and oxidative stress (23). Moreover, type 2 diabetes and hypertension have been extensively associated with impaired kidney function, and although least understood, it should be noted that obesity has been recently correlated with lower eGFR and chronic kidney disease (24). Nevertheless, continuous health interventions involving regular monitoring of BMI and lifestyle changes have led to improved renal function outcomes $(25,26)$. Interestingly, a populationbased longitudinal study concluded that individuals with MetS are at a higher risk of developing kidney disease, although the risk is reduced or disappears when MetS is reversed (27). To the best of our knowledge, this is the first study that shows the significant association of kidney disease and the MetS in heavy drinkers.

Regarding the role of serum GGT, its association with MetS has been described in general population and cohort studies $(28,29)$. Elevated serum GGT is a marker of intracellular liver triglyceride accumulation that has been associated with overweight/obesity and insulin resistance, regardless of alcohol consumption $(28,30)$.

Moreover, elevated serum GGT may reflect the impact of oxidative stress and chronic inflammation and both conditions are closely associated with MetS $(31,32)$. In fact, serum GGT is an early marker for atherosclerosis, arterial stiffness and plaque (33).

Hyperuricemia has been associated with MetS and coronary artery disease regardless of alcohol consumption $(34,35)$. As for the association between SUA and MetS, a recent study by our group described a close relationship between hyperuricemia and serum GGT in AUD patients (14). Furthermore, individuals with elevated SUA levels are at risk of developing chronic renal dysfunction according to a systematic review including 13 studies and 190.000 participants (36).

Epidemiologic observations have suggested an independent association between age and Mets. Prevalence of MetS increases up to the sixth decade of life in men and the seventh decade in women and then decline $(37,38)$. Our results show that prevalence of MetS starts to decrease a decade earlier as compared to the general population thus pointing out the need for future research in individuals with an alcohol-induced pro-inflammatory environment (39).

This study had several limitations that must be mentioned. First, the cross-sectional design did not support conclusions regarding the causality of the findings. Moreover, in this case-series there were no 
variables related to socioeconomic status and lifestyle, such as diet and physical activity and both conditions have been associated with MetS (40). Furthermore, this study lacked indicators of psychiatric comorbidity and use of antipsychotic drugs that might influence the appearance of metabolic side effects including overweight/obesity (20). Finally, the results of this study focused only on patients with alcohol abuse or dependence, and they cannot be generalized to individuals with moderate alcohol consumption. However, the main strength of this study is the number of behavioral and biological variables to analyze associations of MetS in a poorly studied population.

\section{Conclusions}

In conclusion, age, eGFR, serum GGT, and SUA were independently associated with MetS which suggests an alcohol-induced pro-inflammatory environment that could play a role in the development of metabolic, kidney and liver-related complications.

\section{Abbreviations}

\section{ALT}

alanine aminotransferase

AUD

alcohol use disorder

$\mathrm{BMI}$

body mass index

$\mathrm{Cl}$

confidence interval

CVD

cardiovascular disease

eGFR

estimated glomerular filtration

ESR

erythrocyte sedimentation rate

GGT

gamma-glutamyl transferase

IQR

interquartile range

MetS

metabolic syndrome

OR

odds ratio

SUA

serum uric acid 


\section{Declarations}

Ethics approval and consent to participate: All patients provided written informed consent, and the study design was approved by the Ethics Committee of the Hospital Universitari Germans Trias i Pujol (approval number CEXT042013). The methods complied with the ethical standards for medical research and the principles of good clinical practice in accordance with the World Medical Association's Declaration of Helsinki.

Consent for publication: Not applicable

Availability of data and materials: The datasets used and/or analysed during the current study are available from the corresponding author on reasonable request

Competing interests: The authors declare that they have no competing interests

Funding: This work was supported by the Ministry of Science, Innovation and Universities, Carlos III Health Institute (ISCIII), European Fund for Regional Development (FEDER), Network for Cooperative Research in Health (RETICS), Spain [grant numbers RD16/0017/0003, PI17/00174, PI20/00883; the Ministry of Health, Social Services and Equality, National Plan on Drugs (PNSD), Spain [grant numbers 2018/020 and 2020/024] and, the Agency for Management of University and Research Grants, Government of Catalonia [grant number 2017SGR316].

Author contributions: AHR, AS, and RM conceived and designed the study. RM and AS obtained research funding. FB and RM undertook recruitment of patients. AS undertook the statistical analysis. AHR, AS and RM reviewed the literature and made contributions to the interpretation of data. All authors (AHR, AS, FB, CPM, ICS, CGM, AS, RB, RM) contributed substantially to its revision. All the authors have revised and approved the final manuscript.

Acknowledgements: Not applicable

\section{References}

1. Rochlani Y, Pothineni NV, Kovelamudi S, Mehta JL. Metabolic syndrome: pathophysiology, management, and modulation by natural compounds. Ther Adv Cardiovasc Dis. 2017 Aug;11(8):215-25.

2. Justice AC, Modur P, Tate S, Althoff JP, Jacobson KN, Gebo LP. KA, et al. Predictive Accuracy of the Veterans Aging Cohort Study Index for Mortality With HIV Infection. JAIDS J Acquir Immune Defic Syndr;62(2):149-63.

3. Scuteri A, Laurent S, Cucca F, Cockcroft J, Cunha PG, Mañas LR, et al. Metabolic syndrome across Europe: different clusters of risk factors. Eur J Prev Cardiol. 2015 Apr;22(4):486-91.

4. Alberti KG, Zimmet PZ. Definition, diagnosis and classification of diabetes mellitus and its complications. Part 1: diagnosis and classification of diabetes mellitus provisional report of a WHO 
consultation. Diabet Med. 1998 Jul;15(7):539-53.

5. Einhorn D, Reaven GM, Cobin RH, Ford E, Ganda OP, Handelsman Y, et al. American College of Endocrinology position statement on the insulin resistance syndrome. Endocr Pract;9(3):237-52.

6. Alberti KGMM, Zimmet P, Shaw J. Metabolic syndrome-a new world-wide definition. A Consensus Statement from the International Diabetes Federation. Diabet Med. 2006 May;23(5):469-80.

7. Grundy SM, Cleeman JI, Daniels SR, Donato KA, Eckel RH, Franklin BA, et al. Diagnosis and management of the metabolic syndrome: an American Heart Association/National Heart, Lung, and Blood Institute Scientific Statement. Circulation. 2005 Oct;112(17):2735-52.

8. Alberti KGMM, Eckel RH, Grundy SM, Zimmet PZ, Cleeman JI, Donato KA, et al. Harmonizing the metabolic syndrome: a joint interim statement of the International Diabetes Federation Task Force on Epidemiology and Prevention; National Heart, Lung, and Blood Institute; American Heart Association; World Heart Federation; International. Circulation. 2009 Oct;120(16):1640-5.

9. Ference BA, Kastelein JJP, Catapano AL. Lipids and Lipoproteins in 2020. JAMA - Journal of the American Medical Association; 2020 Aug 11;324(6):595-596.

10. Simmons RK, Alberti KGMM, Gale EAM, Colagiuri S, Tuomilehto J, Qiao Q, et al. The metabolic syndrome: Useful concept or clinical tool? Report of a WHO expert consultation. Diabetologia; 2010 Apr;53(4):600-5.

11. Tauler P, Bennasar-Veny M, Morales-Asencio JM, Lopez-Gonzalez AA, Vicente-Herrero T, De PedroGomez J, et al. Prevalence of premorbid metabolic syndrome in Spanish adult workers using IDF and ATPIII diagnostic criteria: Relationship with cardiovascular risk factors. PLoS One; 2014 Feb 20;9(2).

12. Welty FK, Alfaddagh A, Elajami TK. Targeting inflammation in metabolic syndrome. Transl Res. 2016 Jan;167(1):257-80.

13. Jarvis CM, Hayman LL, Braun LT, Schwertz DW, Ferrans CE, Piano MR. Cardiovascular risk factors and metabolic syndrome in alcohol- and nicotine-dependent men and women. J Cardiovasc Nurs. 2007 Nov;22(6):429-35.

14. Hernández-Rubio A, Sanvisens A, Bolao F, Pérez-Mañá C, García-Marchena N, Fernández-Prendes C, et al. Association of hyperuricemia and gamma glutamyl transferase as a marker of metabolic risk in alcohol use disorder. Sci Rep. 2020;10:20060.

15. Abdul-Rahman AK, Card TR, Grainge MJ, Fleming KM. All-cause and cause-specific mortality rates of patients treated for alcohol use disorders: A meta-analysis. Subst Abus. 2018 Oct;39(4)(2):509-17.

16. Kim S-J, Kim D-J. Alcoholism and diabetes mellitus. Diabetes Metab J. 2012 Apr;36(2):108-15.

17. Levey AS, Stevens LA, Schmid CH, Zhang YL, Castro AF, Feldman HI, et al. A new equation to estimate glomerular filtration rate. Ann Intern Med. 2009 May;5(9):604-12. 150(.

18. Ryan MC, Fenster Farin HM, Abbasi F, Reaven GM. Comparison of waist circumference versus body mass index in diagnosing metabolic syndrome and identifying apparently healthy subjects at increased risk of cardiovascular disease. Am J Cardiol. 2008 Jul;102(1):40-6. 
19. Jayedi A, Soltani S, Zargar MS, Khan TA, Shab-Bidar S. Central fatness and risk of all cause mortality: systematic review and dose-response meta-analysis of 72 prospective cohort studies. BMJ. 2020 Sep;370:m3324.

20. Vancampfort D, Hallgren M, Mugisha J, De Hert M, Probst M, Monsieur D, et al. The Prevalence of Metabolic Syndrome in Alcohol Use Disorders: A Systematic Review and Meta-analysis. Alcohol Alcohol. 2016 Sep;51(5):515-21.

21. Guallar-Castillón P, Pérez RF, López García E, León-Muñoz LM, Aguilera MT, Graciani A, et al. Magnitude and Management of Metabolic Syndrome in Spain in 2008-2010: The ENRICA Study. Rev Española Cardiol (English Ed). 2014 May;67(5):367-73.

22. Kassi E, Pervanidou P, Kaltsas G, Chrousos G. Metabolic syndrome: Definitions and controversies. BMC Med. 2011 May 5;9.

23. Zhang X, Lerman LO. The metabolic syndrome and chronic kidney disease. Translational Research Mosby Inc. 2017;183:4-25.

24. Garofalo C, Borrelli S, Minutolo R, Chiodini P, De Nicola L, Conte G. A systematic review and metaanalysis suggests obesity predicts onset of chronic kidney disease in the general population. Kidney Int. 2017 May 1;91(5):1224-35.

25. Yamagata K, Makino H, Iseki K, Ito S, Kimura K, Kusano E, et al. Effect of behavior modification on outcome in early- To moderate-stage chronic kidney disease: A cluster-randomized trial. PLoS One. 2016 Mar 1;11(3).

26. Câmara NOS, Iseki K, Kramer H, Liu ZH, Sharma K. Kidney disease and obesity: Epidemiology, mechanisms and treatment. Nat Rev Nephrol. 2017;13:181-90.

27. Park S, Lee S, Kim Y, Lee Y, Kang MW, Han K, et al. Reduced risk for chronic kidney disease after recovery from metabolic syndrome: A nationwide population-based study. Kidney Res Clin Pract. 2020 Jun 1;39(2):180-91.

28. Lee DS, Evans JC, Robins SJ, Wilson PW, Albano I, Fox CS, et al. Gamma glutamyl transferase and metabolic syndrome, cardiovascular disease, and mortality risk: the Framingham Heart Study. Arterioscler Thromb Vasc Biol. 2007 Jan;27(1):127-33.

29. Voruganti VS, Göring HHH, Mottl A, Franceschini N, Haack K, Laston S, et al. Genetic influence on variation in serum uric acid in American Indians: the strong heart family study. Hum Genet. 2009 Nov 10;126(5):667-76.

30. Kunutsor SK, Apekey TA, Seddoh D. Gamma glutamyltransferase and metabolic syndrome risk: a systematic review and dose-response meta-analysis. Int J Clin Pract. 2015 Jan;69(1):136-44.

31. Bonomini F, Rodella LF, Rezzani R. Metabolic syndrome, aging and involvement of oxidative stress. Aging Dis. 2015 Mar;6(2):109-20.

32. Bo S, Gambino R, Durazzo M, Guidi S, Tiozzo E, Ghione F, et al. Associations between gammaglutamyl transferase, metabolic abnormalities and inflammation in healthy subjects from a population-based cohort: a possible implication for oxidative stress. World J Gastroenterol. 2005 Dec;11(45):7109-17. 
33. Koenig G, Seneff S. Gamma-Glutamyltransferase. A Predictive Biomarker of Cellular Antioxidant Inadequacy and Disease Risk. Dis Markers. 2015;2015:818570.

34. Lai X, Yang L, Légaré S, Angileri F, Chen X, Fang Q, et al. Dose-response relationship between serum uric acid levels and risk of incident coronary heart disease in the Dongfeng-Tongji Cohort. Int $\mathrm{J}$ Cardiol. 2016 Dec 1;224:299-304.

35. Yadav D, Lee ES, Kim HM, Choi E, Lee EY, Lim JS, et al. Prospective study of serum uric acid levels and incident metabolic syndrome in a Korean rural cohort. Atherosclerosis. 2015 Jul;241(1):271-7.

36. Li L, Yang C, Zhao Y, Zeng X, Liu F, Fu P. Is hyperuricemia an independent risk factor for new-onset chronic kidney disease?: A systematic review and meta-analysis based on observational cohort studies. BMC Nephrology. 2014;15:122.

37. Razzouk L, Muntner P. Ethnic, gender, and age-related differences in patients with the metabolic syndrome. Curr Hypertens Rep. 2009 Apr;11(2):127-32.

38. Jiang B, Zheng Y, Chen Y, Chen Y, Li Q, Zhu C, et al. Age and gender-specific distribution of metabolic syndrome components in East China: role of hypertriglyceridemia in the SPECT-China study. Lipids Health Dis. 2018 Apr;17(1):92.

39. Yamaki N, Matsushita S, Hara S, Yokoyama A, Hishimoto A, Higuchi S. Telomere shortening in alcohol dependence: Roles of alcohol and acetaldehyde. J Psychiatr Res. 2019 Feb;109:27-32.

40. Wu HF, Tam T, Jin L, Lao XQ, Chung RY-N, Su XF, et al. Age, gender, and socioeconomic gradients in metabolic syndrome: biomarker evidence from a large sample in Taiwan, 2005-2013. Ann Epidemiol. 2017 May;27(5):315-22.e2.

\section{Figures}




\section{Prevalence of MetS}

Male $\square$ Female

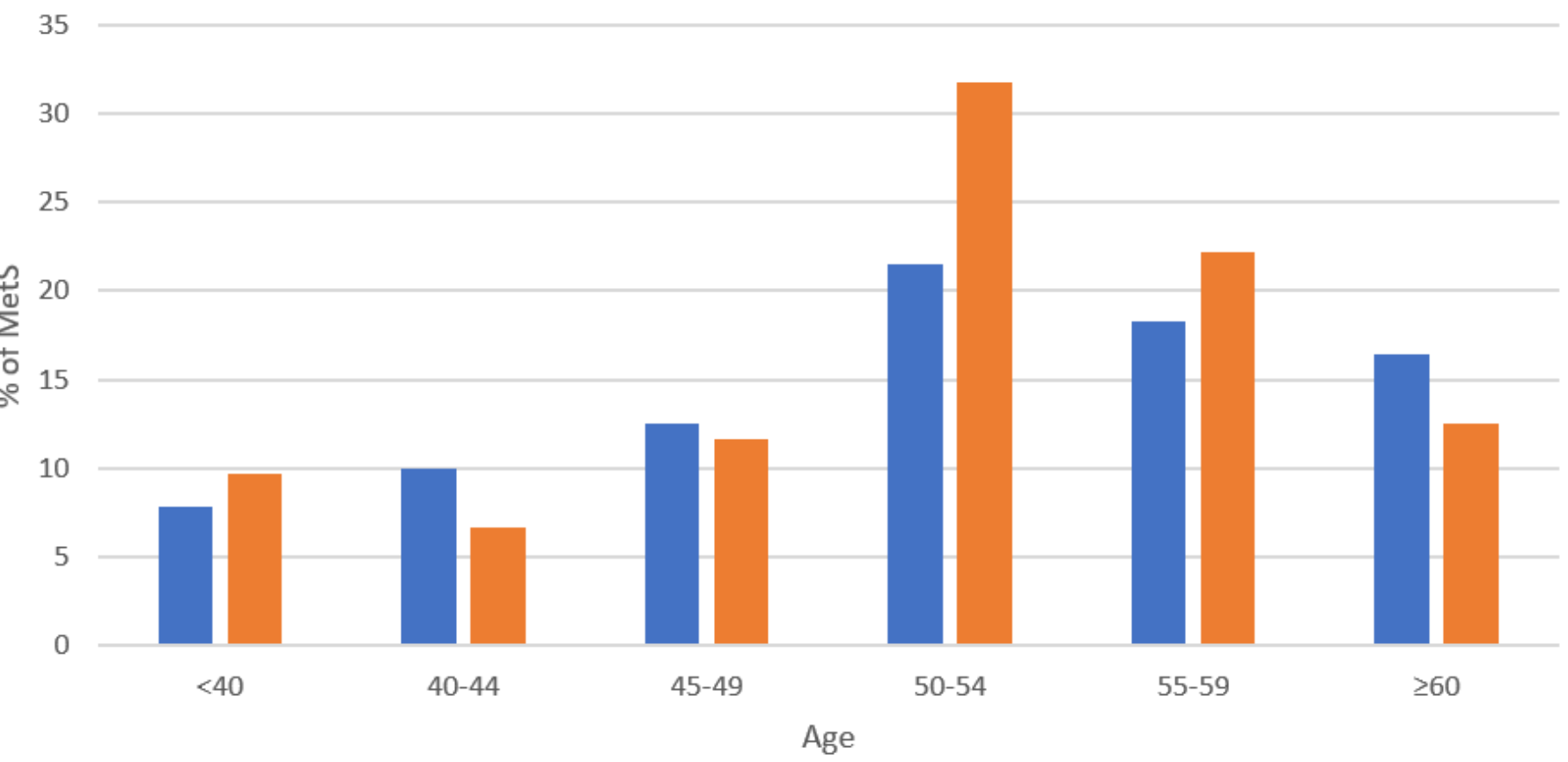

\section{Figure 1}

Prevalence of MetS in 728 patients with alcohol abuse or dependence according to age groups and sex.

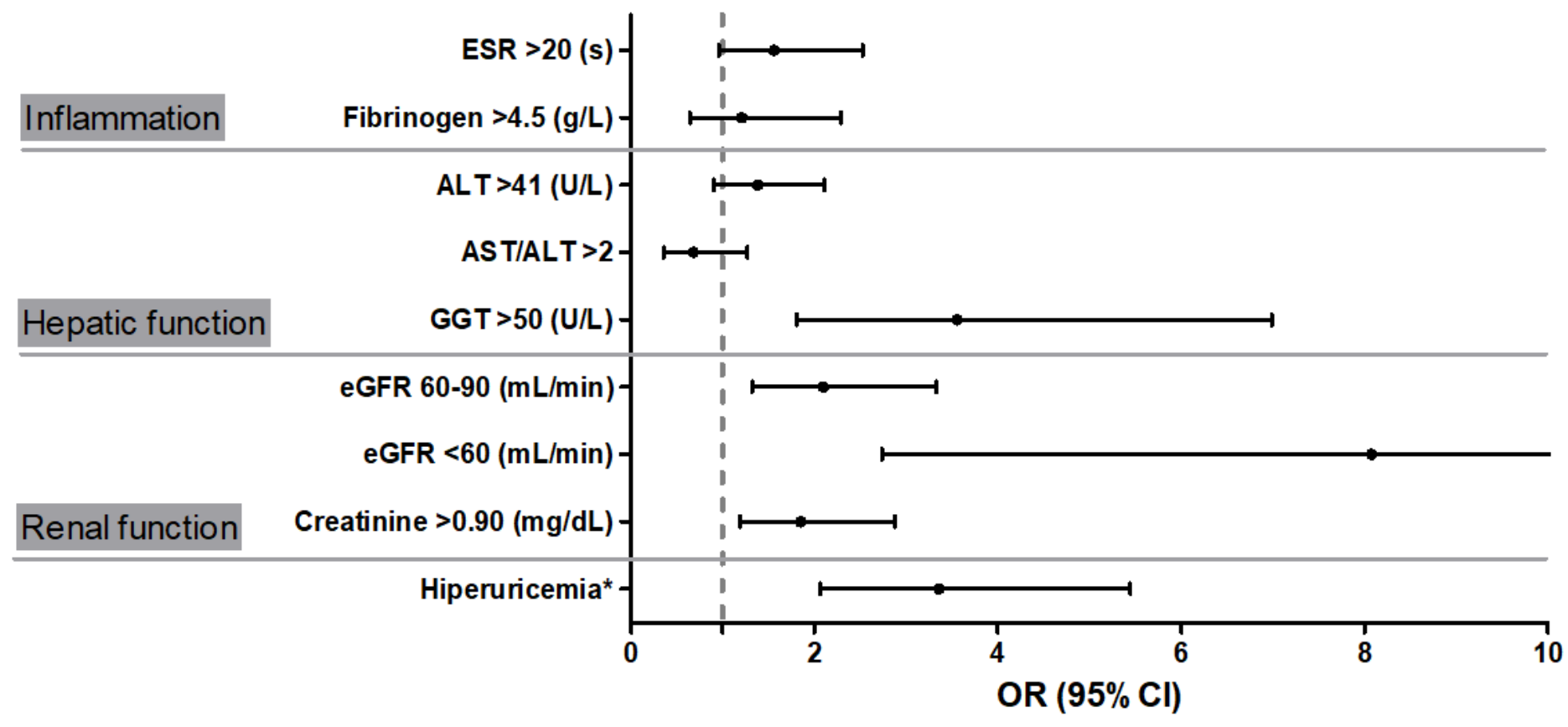

* urate $>7.2 \mathrm{mg} / \mathrm{dL}$ in men and $>6 \mathrm{mg} \mathrm{dL}$ in women

Figure 2 
Associations of MetS with inflammatory markers, liver parameters and renal function of 728 patients with alcohol abuse or dependence. ESR: erythrocyte sedimentation rate; eGFR: estimated glomerular filtration rate; AST: aspartate aminotransferase, ALT: alanine aminotransferase; GGT: gamma-glutamyl transferase; OR: odds ratio 